\title{
触 New Disease Reports \\ First report of Pseudomonas syringae pv. aesculi on horse chestnut in Switzerland
}

\author{
J.B. Meyer ${ }^{1 *}$, M. Brunner ${ }^{2}$ and D. Rigling ${ }^{1}$ \\ ${ }^{1}$ Swiss Federal Institute for Forest, Snow and Landscape Research WSL, CH-8903 Birmensdorf, Switzerland; ${ }^{2}$ Matthias \\ Brunner AG, Restelbergstrasse 64, CH-8044 Zürich
}

*E-mail: joana.meyer@wsl.ch

Received: 24 Nov 2015. Published: 25 Apr 2016. Keywords: Aesculus hippocastanum, bacterial plant disease

In 2011 in a public park in Rapperswil-Jona (Switzerland), bleeding cankers (Fig. 1) were observed on 42 out of 300 horse chestnut trees (Aesculus hippocastanum). On March 2015, four to six bark samples were taken from each of three affected trees using a sterilised cork borer $(2 \mathrm{~mm}$ in diameter). The bark samples were removed from either the centre of the bleeding cankers or from the edge of the necrotic orange-brown lesions (Fig. 2), which became visible after removing the outer bark. Bacterial isolation from the bark samples was made on selective media as described by Green et al. (2009). To detect fluorescent cultures, bacteria were streaked on King's medium B (King et al., 1954) amended with $50 \mathrm{mg} / \mathrm{l}$ cycloheximide. For species identification, the $\operatorname{gyr} B$ gene was partially sequenced using the primers gyrB-F/gyrB-R (Green et al., 2009) and the 16S rDNA gene using the primers EUB f933/EUB r1387 (Ji et al., 2004). Six fluorescent bacteria were isolated from all types of samples and from all trees, and were identified as P. syringae pv. aesculi based on $100 \%$ identity with $616 \mathrm{bp}$ of the $\operatorname{gyr} B$ gene and as Pseudomonas sp. based on $100 \%$ identity with $415 \mathrm{bp}$ of the $16 \mathrm{~S}$ rDNA gene. Two additional nonfluorescent Pseudomonas sp. and Erwinia billingiae were isolated. The Genbank accession numbers of these sequences are KT965182-KT965197.

Pathogenicity tests were performed with two $P$. syringae pv. aesculi isolates collected during this study (M8597 and M8603), using three-year-old A. hippocastanum saplings. Five replicate saplings were each inoculated through stem cuts with a $5 \mu \mathrm{l}$ drop of a $10^{8} \mathrm{cfu} / \mathrm{ml}$ bacterial suspension. After eight weeks' incubation in a greenhouse at $22 \pm 1^{\circ} \mathrm{C}$, bleeding cankers developed at the inoculation sites of all treated trees, while control trees remained symptomless (Fig. 3). The average lesion lengths produced by isolates M8597 and M8603 were $38.8 \mathrm{~mm}$ (range 18-67 mm) and $31.4 \mathrm{~mm}$ (range $21-52 \mathrm{~mm}$ ), respectively. Koch's postulates were completed by successfully re-isolating the bacteria from all the necrotic lesions.

This is the first detection of $P$. syringae pv. aesculi on horse chestnut trees in Switzerland. The bleeding canker symptoms are moderate and being monitored to follow their progression. Since the outbreak of the disease in Northern Europe (UK and Netherlands) in the early 2000's (Webber et al., 2008), the pathogen has been found in other countries causing economic losses (EPPO, 2009). Isolates M8597 and M8603 have been deposited in the Culture Collection of Switzerland (CCOS) as CCOS950 and CCOS951, respectively.

\section{Acknowledgements}

The authors would like to thank Gabor Reiss for providing horse chestnut saplings and Barbara Meier for DNA sequencing.

\section{References}

EPPO, 2009. A new disease of horse chestnut caused by Pseudomonas syringae pv. aesculi: addition to the EPPO Alert List. EPPO Reporting Service 6, 2009/117.

Green S, Laue B, Fossdal CG, A'Hara SW, Cottrell JE, 2009. Infection of horse chestnut (Aesculus hippocastanum) by Pseudomonas syringae pv. aesculi and its detection by quantitative real-time PCR. Plant Pathology 58, 731-744. http://dx.doi.org/10.1111/j.1365-3059.2009.02065.x

Ji N, Peng B, Wang G, Wang S, Peng X, 2004. Universal primer PCR with DGGE for rapid detection of bacterial pathogens. Journal of Microbiological Methods 57, 409-413.

http://dx.doi.org/10.1016/j.mimet.2004.02.010

King EO, Ward MK, Raney DE, 1954. Two simple media for the demonstration of pyocyanin and fluorescin. Journal of Laboratory and Clinical Medicine 44, 301-307.

Webber JF, Parkinson NM, Rose J, Stanford H, Cook RTA, Elphinstone JG, 2008. Isolation and identification of Pseudomonas syringae pv. aesculi causing bleeding canker of horse chestnut in the UK. Plant Pathology 57, 368. http://dx.doi.org/10.1111/j.1365-3059.2007.01754.x

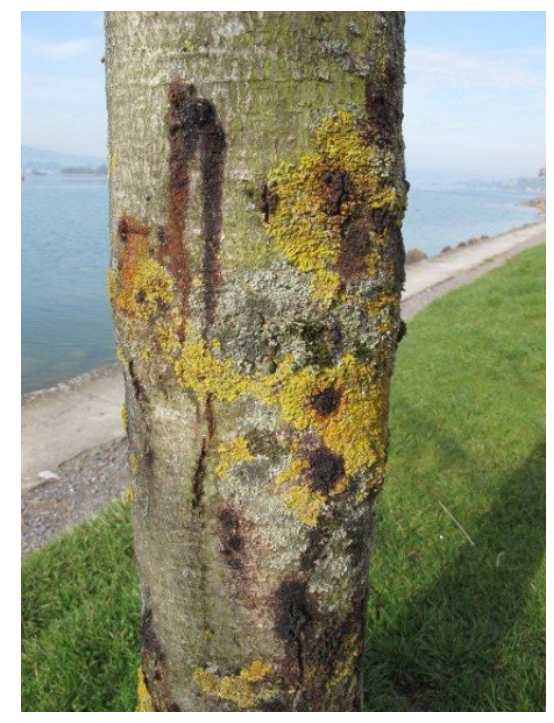

Figure 1

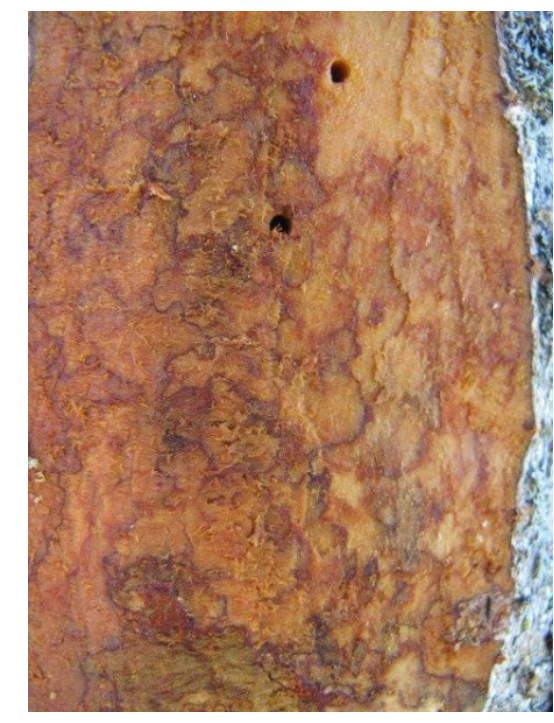

Figure 2

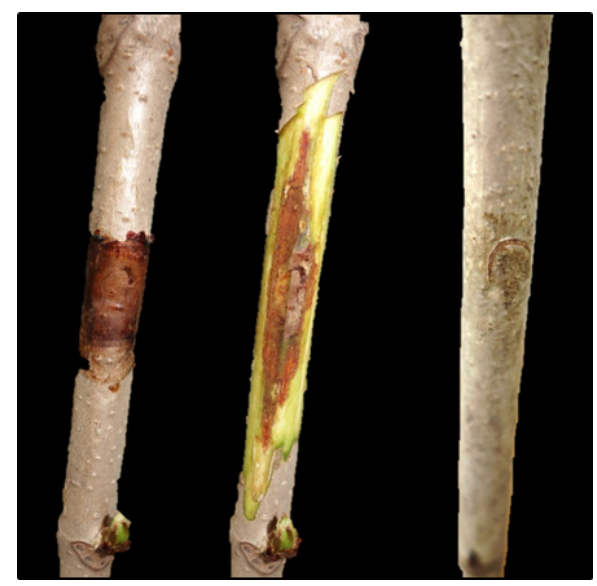

Figure 3

To cite this report: Meyer JB, Brunner M, Rigling D, 2016. First report of Pseudomonas syringae pv. aesculi on horse chestnut in Switzerland. New Disease Reports 33, 19. http://dx.doi.org/10.5197/j.2044-0588.2016.033.019

(C) 2016 The Authors

This report was published on-line at www.ndrs.org.uk where high quality versions of the figures can be found. 